Article

\title{
Climate Change and Virtue: An Apologetic
}

\author{
Mike Hulme ${ }^{1,2}$
}

1 Department of Geography, King's College London, Strand WC2R 2LS, London, UK;

E-Mail: mike.hulme@kcl.ac.uk; Tel.: +44-020-7848-2487

2 Rachel Carson Center for Environment and Society, LMU Münich, Leopoldstr. 11a, Münich D-80802, Germany

Received: 28 April 2014; in revised form: 20 June 2014 / Accepted: 24 June 2014 /

Published: 30 June 2014

\begin{abstract}
The prominent Australian earth scientist, Tim Flannery, closes his recent book Here on Earth: A New Beginning with the words “... if we do not strive to love one another, and to love our planet as much as we love ourselves, then no further progress is possible here on Earth". This is a remarkable conclusion to his magisterial survey of the state of the planet. Climatic and other environmental changes are showing us not only the extent of human influence on the planet, but also the limits of programmatic management of this influence, whether through political, economic, technological or social engineering. A changing climate is a condition of modernity, but a condition which modernity seems uncomfortable with. Inspired by the recent "environmental turn" in the humanities - and calls from a range of environmental scholars and scientists such as Flannery-I wish to suggest a different, non-programmatic response to climate change: a reacquaintance with the ancient and religious ideas of virtue and its renaissance in the field of virtue ethics. Drawing upon work by Alasdair MacIntyre, Melissa Lane and Tom Wright, I outline an apologetic for why the cultivation of virtue is an appropriate response to the challenges of climate change.
\end{abstract}

Keywords: climate change; humanities; virtue; environmental politics; ethics; goodness

\section{Introduction}

The prominent earth scientist, and 2007 Australian of the Year, Tim Flannery closes his recent book Here on Earth: A New Beginning with the words “... if we do not strive to love one another, and to love our planet as much as we love ourselves, then no further progress is possible here on Earth” ([1], 
p. 281). This is a remarkable conclusion to his magisterial survey of the state of the planet under a changing climate. After surveying the deep history of life on Earth and humanity's increasing influence over it, the solution Flannery arrives at is not more knowledge-more striving after science and technology—but a striving after love.

Flannery is not alone amongst contemporary environmental scientists in valorising love. The ecologist Brendon Larson in the peroration to his book Metaphors for Environmental Sustainability reflects: "I can return to the ramblings in the natural world ... falling in love with it, and thus wanting to express that love ... in the most apt words I can” ([2], pp. 228-29). And we don’t have to look much further to locate other prominent environmental scientists and social scientists whose concern for the future of climate on Earth leads them to invoke other human virtues. Sheila Jasanoff in her essay, “Technologies of humility”, published a few years ago in the journal Nature, explains her call for humility as "a plea for policy-makers to cultivate, and for universities to teach, modes of knowing that are often pushed aside in expanding scientific understanding and technological capacity” ([3], p. 33). Alastair McIntosh uses the subtitle 'climate change, hope and the human condition' to his 2008 book Hell and High Water, where for him "Hope is about setting in place the preconditions that might reconstitute life and then getting on with it” ([4], p. 250). And then there is anthropologist Tim Leduc in Climate, Culture, Change suggesting that "wisdom may be the most fundamental factor that inter-disciplinary climate research needs to clarify, as it responds to [climate] warming” ([5], p. 40).

Love, humility, hope and wisdom; in my pursuit of understanding climate change and what it signifies for the world, I am interested in these apparently orthogonal interventions by such authors as they contemplate the state of climate and the fate of the Earth. In all the climate models I have examined, used and criticised over 30 years I have not yet come across a variable for love or an equation for calculating humility. The thermometer may have been essential to tell the story of a warming world, but environmental scientists have not yet invented or seen the need for a hope-ometer. What is it then that draws such scientists and scholars to place the fate of the planet in the hands of such intangible human qualities? These are not qualities that feature in the usual discourse of climate change conducted by political scientists, economists, engineers and environmental scientists-even if they are familiar to virtue ethicists.

In this article I explore this-perhaps surprising-acquaintance by climate and environmental scientists with the ancient idea of virtue. And by virtue I adopt the definition offered by theologian Tom Wright: "practising habits of heart and life that point toward the true goal of human existence” ([6], p. 12). Drawing upon work by Alasdair MacIntyre, Melissa Lane and Tom Wright, I later outline an apologetic for why the cultivation of virtue is an appropriate response to the challenges of climate change. Contrary to the novelist Ian McEwan who claimed with regard to climate change that “Cleverness got us into this problem and I don't think virtue is going to get us out of it” [7], I suggest that virtue may be the most enduring response that we have. But before developing this apologetic I need to explain the dead-end we have reached with regard to climate change. Why have we-and by 'we' I mean knowing politicians, scientists, entrepreneurs, campaigners, citizens_failed to reign-in humanity's growing influence on the world's climate? Why do we talk up climate change, but play dumb when challenged about the response? Why has another global gathering of politicians, diplomats and negotiators—most recently at Warsaw in December 2013—again prevaricated and stalled? 


\section{2. 'The Plan'}

For more than 25 years the conventional view has been that an international political solution to climate change can be negotiated if driven by the engine of science. That is, if a strong enough scientific consensus on the causes and consequences of anthropogenic climate change could be forged and sustained, then the compelling force of such rationality would over-ride the differences in worldviews, beliefs, values and ideologies which characterise the human world. Such a scientific consensus would bring about the needed policy solutions. This is the "If-then" logic of computer programming, the conviction that the right way to tackle climate change is through what Dan Sarewitz at Arizona State University has called “The Plan” [8]. And there are those who still believe in this project. They excoriate others who obstruct and obscure this pure guiding light of rationality-a position adopted, for example, by Naomi Oreskes and Erik Conway in their recent book Merchants of Doubt [9].

From the vantage point of 2014 we can now see that the credibility of such a narrative hinged on a set of circumstances peculiar to the late 1980s and early 1990s. These included: (i) the belief in the 'end of history' and the triumph of (neo-)liberal democracy; (ii) the seeming continued marginalisation of religion in public life; and (iii) the emergence of a globalised environmental science. This latter enterprise secured its first big success in 1987, when the predictive power of the newly minted Earth System science was co-opted by the Montreal Protocol on Substances that Deplete the Ozone Layer. It was the convergence of these circumstances in the years around 1990 that helped fashion the conventional climate change project—“The Plan”—and allowed it to surge forward with optimism.

At the time it seemed entirely reasonable that with one of the last "enemies" of progressive Enlightenment liberalism having been swept away (i.e., communism), a new irrepressible world order would emerge. And it would be one that would now fully exploit the predictive power of fruitful globalised science. The putative threat that a burgeoning carbon-fuelled humanity-thriving, ironically, through the fruit of this very same Enlightenment-was posing to climatic stability would be defused. This project would demonstrate decisively the force of scientific rationality over the fading and divisive powers of religion and ideology. Scientific consensus would forge political consensus and political consensus would yield victory. And victory would be the Salvation of the planet.

\section{Failed Salvation}

This "salvation project" has now run its course, abjectly halted by a combination of the events of December 2009 (the COP15 meeting at Copenhagen and the Climategate fiasco) and the world financial crisis. Even though the project still has its believers, the world has seen another climate conference-COP19 in Warsaw_-pass away. The Kyoto Protocol remains alive-but only on a life support machine-and the haggling amongst developed nations over \$100 billion of new funding for mitigation and adaptation investments in developing countries is yielding very little. The old-guard believers in 'The Plan' are dwindling in number and many are reluctantly and uneasily shifting their beliefs. The world of Rio+20 in 2012 looked and felt very different to the one George H W Bush (senior) inhabited when he made his way to Rio de Janeiro 20 years earlier. Instead of the end of history, what we are witnessing is a flowering of the irrepressible diversity of human beliefs, 
ideologies and scepticisms. This flowering is manifest in various ways: (i) around the world in resurgent religious confidence and vitality; (ii) on the internet through increasingly combative exchanges; and (iii) in the West through a deep questioning of the capitalist neo-liberal paradigm. There is no better example of this latter mood than The Dark Mountain Project in the UK, which announces itself as ‘the new cultural movement for the age of disruption' [10]. This diversity of human beliefs and aspirations is irrepressible because of the foundational human need for alterity: the need to define ourselves in relation to 'the other'. Cosmopolitanism has its limits.

Far from the end of history, then, and the inexorable onward march of the secular project, we are witnessing an overdue reconsideration of the place of rationality in human knowing. There is a challenging re-examination underway of the role of religion in the public sphere [11,12]. Secularisation has taken an unexpected turn. New forms of deliberation and decision-making which accommodate entrenched plurality—both religious and ideological—are having to be invented. This is well illustrated by Bruno Latour's 2013 Gifford Lectures, “Facing Gaia: a new inquiry into natural religion" [13]. We need to recognise that two climates have changed since the late 1980s: local cultural, economic and political climates have changed as much as has the global physical climate. Not surprisingly, cumbersome international efforts at dealing with climate change have been increasingly wrong-footed by these new cultural and political dynamics. And in the vanguard of those who have realised the futility of more of the same tired programmatic climate change agenda are some progressive environmentalists. These fall into two camps.

On the one hand are those like Ted Nordhaus and Michael Shellenberger in the United States who announced a few years ago 'the death of environmentalism'. At the Breakthrough Institute they have inspired a new breed of climate pragmatists who are promoting a universal call for human dignity in development to be at the centre of a new re-constructed climate policy agenda. On the other hand are those environmental thinkers who realise the need to engage in more direct public argument over cultural values, in particular to question the dominant extrinsic values which drive material consumption. This is epitomized for example by Tom Crompton's work with the UK environmental NGOs and his strategy document Common Cause: The Case for Working with Values and Frames [14].

These two reactions to the sterile politics of climate change - to the futility of "The Plan"-adopt different reasoning and language. But they are united in their conviction that scientific knowledge about climate cannot be the primary motivator and driving engine of change. Indeed, the more trenchant critics would now argue that the product of climate science-uncertain predictions presented as a solidified and settled consensus_-has perhaps acted as much as an obstacle as it has a spur to policy enactment. Science has done what it can. It has shown us the extent of the interpenetration of the human and the material- “we are without nature” [15]; the Earth's climate is now a prosthetic to humanity. And yet we remain confronted with the limits of our programmatic responses to climate change, whether they be political, economic, technological or social engineering. Climate change is a condition of late modernity, yet it is a condition which modernity does not know how either to alleviate or to live with. 


\section{A Disposition, Not a Plan}

It is in the context of this historical trajectory and these cultural dynamics of environmentalism that I suggest a different direction. In my pursuit of the idea of climate change I want to focus attention on the ancient idea of virtue, the possibility that the "wickedness" of climate change as a problem demands a flowering of human "goodness". Some of the language that I adopt will seem far away from the usual vocabulary of climate change- “tipping points”, "two degrees”, “emissions trading”, "low carbon economy”, “climate adaptation”. But listen carefully to the new voices speaking in the desertsome of whom I mentioned at the beginning — and one will hear a new language emerging around the fringes of climate change research, discourse and action... the language of empathy, story-telling, trust, wisdom, humility, integrity, faith, hope and love. I want to suggest that this is a vocabulary which, carefully deployed and realised, constitutes a re-discovery of virtue.

I need to be clear. A focus on human virtue is not a political programme. This is no techno-fix for climate change, no system for Earth governance, no exercise in social engineering. And the argument that I make reaches beyond a narrow naturalistic (utilitarian) approach to ethics and morality, such as recently developed by Sam Harris in his book The Moral Landscape [16]. Those who were disappointed with my earlier book Why We Disagree about Climate Change [17] because they interpreted it as evasive, will probably continue to be disappointed. Indeed, the seeds of my current line of thinking were already sown in Why We Disagree, as environmental commentator Richard D North astutely observed in his review of the book: "Mike Hulme's point is that Man's response to anthropogenic global warming ought to transcend thinking about agency, efficacy or instrumentality. Anthropogenic global warming ought to be the catalyst for a redesign of Man, rather than of a human attempt to redesign the climate he lives in. Anthropogenic global warming should thus be seen reflexively. It's about what anthropogenic global warming works on Man, not what Man works on climate” [18]. So I am certainly not offering to 'solve' climate change, nor even suggesting it can be solved.

But the position I develop allows, I believe, the secular project to engage with climate change-at least the secular project as defined by philosopher Charles Taylor. In A Secular Age [19], Taylor argues that the dilemma of secularism is not how to manage, position or suppress religion. Rather it is a problem of how diversity, plurality and alterity are recognised and respected in political decisionmaking in contemporary societies. This is true even in cosmopolitan societies. Perhaps it is true especially in cosmopolitan societies. In conversation with Taylor in 2009, sociologist Craig Calhoun remarked: "The public sphere is ... a realm of cultural formation in which argument is not the only important practice ... creativity and ritual, celebration and recognition are all important. [The public sphere] includes the articulation between deep sensibilities and explicit understandings and it includes the effort-aided sometimes by prophetic calls to attention - to make the way we think and act correspond to our deepest values or moral commitments” ([12], pp. 132-33).

At the end of Why We Disagree, I drew attention to the very acute dilemma climate change presents us with. It is the challenge of embarking on a global project of climate management (or even engineering) when the very values required to design and deliver such a project are deeply contested. It is a dilemma which science is powerless to resolve. Worse still; by seeking to use science as the primary means to resolve the dilemma, we are obscuring the nature of the dilemma itself. Climate 
change thus operates as the exemplar of a much wider conundrum with which political philosophers and science studies scholars continue to struggle: what sources of authority are adequately founded, and appropriately transcendent, to justify and empower political projects which reach beyond conventional jurisdictions? There are a variety of responses to this conundrum as it applies to climate change. My response here draws upon humanist values and traditions, both religious and non-religious. It recognises the limitations of modernity and recognises the multiplicities of knowledges (different rationalities) that remain potent in the world today. It extends my horizons beyond the natural sciences and social sciences, with which I primarily worked in Why We Disagree, towards the environmental humanities, in particular the deployment of virtue ethics alongside geographical sensibility and imagination (see also Sandler and Cafaro’s book Environmental Virtue Ethics [20]).

\section{Virtue}

I mentioned before that for some environmental commentators, such as Tom Crompton, the challenges of climate change and the failure of "The Plan" has led to a public questioning of values. But for others, the searching has gone deeper. For them, the idea of climate change has been less a catalyst for re-shaping human values than it has been a provocation to re-discover the nature and practice of what we may call, along with the ancients, human virtue: this tried and tested exercise in contemplation, self-discovery and human living. Or, in the words of Calhoun above, "to make the ways we think and act, correspond to our deepest values or moral commitments”. Taking seriously the challenges to human well-being raised by climate change, some entrepreneurial humanists and theologians - and, more surprisingly, some scientists such as those with whom I opened this essayhave asked us to contemplate anew virtues such as wisdom, humility, integrity, faith, hope and, above all, the virtue of love.

So let me sketch out an apologetic for such calls to virtuous living as they apply to climate change: to show how the exercise of virtue can transform both the quality of public deliberation and the efficacy of the human individual as a public actor (cf. [21]). Practicing virtue can offer substantive, instrumental and normative benefits for dealing with the challenges of climate change. Substantively, through the exercise of virtue public knowledge of climate change will be modified, if not transformed. Instrumentally, when contributing to public discourse and deliberation about responses to climate change, the exercise of virtue can inspire and deliver change. And, normatively, in the personal realm it is right and good to be virtuous: virtue is indeed the true telos of Man. I start by emphasising the relevance of individual virtue when engaging with the idea of climate change, drawing upon Christian tradition and particularly the work of Tom Wright, ex-Bishop of Durham and now professor of New Testament and Early Christianity at the University of St. Andrews, in his book Virtue Reborn [6]. I then very briefly engage with two other more collective applications of virtue philosophy as advanced by particular authors: the idea of civic virtue, persuasively laid out by political scientist Melissa Lane in her recent book Eco-Republic: Ancient Thinking for a Green Age [22] and virtue ethics, made popular in recent years by the Catholic philosopher Alasdair MacIntyre in his classic work After Virtue [23], and recently reviewed by Guy Axtell and Philip Olson [24].

Some words first, then, about the exercise of individual virtue in the context of climate change. There are of course many lists of human virtues, from that of Aristotle onwards. I am not particularly 
interested in a close scrutiny of the different logics behind these various lists, other than to note that they share one common feature: they encompass those qualities which, if owned, will enable an individual to secure eudaimonia: a state of blessedness, happiness, well-being. Whether they be Aristotelian, Pauline or more contemporary, virtues are recognised by the prevailing culture as enabling human life to be lived at its best. I wish here to consider the virtues of wisdom, humility, integrity, faith, hope and love, and I offer a brief word about each in the context of climate change.

There has been a resurgence of interest in the idea of wisdom, both as embodied in traditional human cultures or religions, but also as understood as a form of knowledge in its own right. We might approach the virtue of wisdom through the idea of phronesis - practical wisdom or "expert knowledge in the fundamental pragmatics of life” ([25], p. 188)—as popularised by social scientist Bent Flyvbjerg [26] and by Alasdair MacIntyre. Or we might approach wisdom as psychologist Robert Sternberg has done in terms of balance [27] — the wise person knows how to weigh competing interests and strategies across the temporal, the narcissistic and the geographical dimensions of living. Either way, paying greater attention to the search for, and the exercise of, wisdom counteracts deficiencies in modernist and reductionist forms of knowledge about climate change.

Particular forms of knowledge or technology may also be critiqued through the virtue of humility. Humility draws attention to the limits to scientific knowledge, especially such knowledge of the climatic future with its essential openness and indeterminacy. Various authors have valorised humility in this context and contrasted it with displays of hubris in much climate science research, writing and advocacy. This contrast is revealed most acutely perhaps in the new discourse of planetary climate engineering, as Clive Hamilton has shown [28]. More broadly, Sheila Jasanoff makes the case for humility in the design of climate policies: "Policies based on humility might: redress inequality before finding out how the poor are hurt by climate change; value greenhouse gases differently depending on the nature of the activities that give rise to them; and uncover the sources of vulnerability in fishing communities before installing expensive tsunami detection systems” ([3], p. 33).

Third, integrity is an important virtue in the context of trust. This was acutely observed in the controversies surrounding the emails released from the Climatic Research Unit at the University of East Anglia a few years ago. Were climate scientists to be trusted for the quality of their work and for the integrity of their dealings with colleagues and opponents alike? What norms and values guided their behaviour and were these recognised to be virtuous in wider cultural settings? The virtue of integrity also draws attention to the eternal human struggle for personal lives to be lived with honesty or, in the language of social psychologists examining climate change and pro-environmental behaviours, by closing the "value-action gap": we do not execute what we profess. Attention to such matters would, for example, draw upon ideas of professional and practice-centred virtue ethics [29].

Faith can be considered a virtue and it too plays a central part in relationships of trust. And faith is an integral part of the scientific endeavour as much as it is central in social relations. More than a virtue, faith becomes a necessity. An examination of faith becomes an examination of the relationship between belief and doubt, between "certainty" and "uncertainty". Faith is the way in which humans navigate between the poles of dogma and ignorance and it applies to secular or personal knowledge as much as to religious or spiritual knowledge. We can see quickly how this becomes relevant in the context of climate change knowledge and discourse. But in the context of responding to climate 
change this raises the key question "Faith in what?"-in science, technology, political authority, democracy, deities, the idea of progress?

And so faith is inseparable from the virtue of hope: Faith in what? Hope for what? Hope is one of the most important of virtues, even if it goes largely unrecognised in Aristotelian or other secular lists. Hope captures the human relationship with the future. If human knowledge is inescapably bound up with the notion of faith, then our relationship with the future is written in the language of hope (see [30]). Of course we may see the general future-or our own personal future-as hopeful or hopeless, but the virtue of hope captures something about the unquenchable human desire for something better. Hope, then, is a virtue which needs nourishing, in both public and personal settings.

Finally there is the virtue of love. But what is love? When Tim Flannery invoked love at the end of his book Here on Earth he most likely was thinking of the idea of biophilia-literally, the love of living things - introduced by Edward O Wilson in his eponymous 1984 book [31] and further developed by Steve Kellert at Yale University. But love is multi-faceted and perhaps ineffable, as countless human thinkers, poets, prophets and song-writers have explored through the ages. C S Lewis offered his own attempt to grasp the complexity of love in The Four Loves [32], in which he laid out a Christian typology of love according to affection (storge), friendship (philia), sex (eros) and charity (agape). Love in the forms of philia and agape-and its close companions, compassion and self-sacrifice — needs cultivating in public and private spheres.

\section{Civic Virtue and Virtue Ethics}

Let me now consider how this commitment to virtue as a guiding disposition in response to climate change can operate in different settings. First, the idea of civic virtue: the cultivation of personal habits which can transform the success of the community. In Eco-Republic, Princeton scholar Melissa Lane revisits Plato's model for defining the relationship between society and the individual—what Plato called "the city and the soul". At the heart of Plato's argument was that the exercise of individual virtues - the pursuit of the good-in public life matters profoundly for the well-being and stability of a just society. Or as the Jewish proverb from about 500 years before Plato claimed: "Through the blessing of the upright a city is exalted, but by the mouth of the wicked it is destroyed" [33].

Lane extends Plato's argument in two ways. First, she shows how in the contemporary world 'the city' embraces material planetary ecologies, most notably the climate, upon which human sustenance crucially depend. This is the eco-turn of Plato's Republic. Second, she contends that the guardianship of civic virtue is not the preserve of Plato's elite-the wise rulers-but is a role to which all participants in the Republic are called. This, then, is the democratic turn. And this requires a more virtuous, engaged and demonstrative role for individual human agency in the demos. (This argument is also developed by Colin Farelly [34]). Here virtue ethics and discourse ethics meet. As Tom Wright describes in Virtue Reborn, "We are going to need [virtue] in the days to come, as world population increases, food sources and supply chains present new problems and the world's climate changes alarmingly. We cannot assume that the whole world will steadily become more and more dominated by Western-style liberal democracy, with people meekly voting every once in a while and doing their own thing between elections” ([6], p. 201). 
And then finally a brief mention of virtue ethics and climate change. From MacIntyre's classic defence of virtue ethics [23] let me highlight two points which I think are relevant for thinking about climate change. First is his historicisation of the arguments among the three main families in ethical theory - consequentialist, Kantian and virtue-based. For MacIntyre, consequentialist and deontological ethics in Western tradition have become detached in recent centuries from any larger moral narrative in which they may originally have been grounded in. For him they have lost authenticity and power as a consequence. This is an outcome of modernity, the same modernity—we might claim-which has placed humans as controller of the Earth's climate. And as contemporary climate ethicists such as Dale Jamieson and Stephen Gardiner have argued [35,36], a condition created by modernity requires a response guided by more than the ethics of that same modernity. Or to quote Einstein: "We can't solve problems by using the same kind of thinking we used when creating them”. The second point to emphasise is how, for MacIntyre, morals and virtues can only be comprehended through their relation to the community from which they arise. Rather than deriving our principles of justice from behind an imagined Rawlsian veil of ignorance, which detaches and abstracts us from our social relationships and cultural commitments, MacIntyre's virtue ethics commits us to derive our ethics from within these inter-human matrices of meaning and belonging. And for me this offers a more credible, situated and plural way—not necessarily an easier or more universal way_of thinking about the intractable ethics of climate change.

\section{How to Proceed?}

The above comments are only an initial outline of arguments from an ex-climate scientist that may be put forward for a virtue-based engagement with the challenges raised by climate change. For some I am sure the cultivation and exercise of virtue is just too abstract, too philosophical, to count as 'climate change action'. Indeed, as Zyl observes, “Critics of virtue ethics have argued that its focus on character rather than action, as well as its rejection of universal rules of right action, renders virtue ethics unable to shed much might on the question of what ought and ought not to be done in specific situations" ([37], abstract). Surely something more ambitious and programmatic is called for? "It is Hulme again indulging in defeatism and quietism", I hear them say. "He is running away from the real challenges of climate change". But let me finish with a few short reflections on two different practical traditions for cultivating virtue-one ancient and religious, and one contemporary and secularsuggesting that the cultivation of virtue is in fact far from abstract, even if it doesn't stop climate changing.

The ancient tradition I offer comes from the Christian faith. Bishop David Atkinson has explained how climate change challenges Christian theology and practice: "the questions posed by climate change reach to the heart of faith: our relationship to God's earth and to each other; the place of technology; questions about sin and selfishness, altruism and neighbour love; what to do with our fears and vulnerabilities; how to work for justice especially for the most disadvantaged parts of the world and for future generations” [38]. A Christian response to climate change therefore involves the community of believers, in theological terms 'the body of Christ'. And since one of the abiding goals of Christian community is the pursuit of holiness, Christians need to ask how virtue can be acquired and exercised? Or as Tom Wright puts it, “How can we acquire that complex 'second nature' which will enable us to grow up as genuine human beings” ([6], p. 220). Wright then offers a virtuous circle 
in which five elements work together to cultivate character: community, stories, scripture, practices, examples. One can recognise in this schema elements that are not unique to Christian tradition. They are ones that can be developed in many different cultural settings by paying attention to: the wisdom of the past; human life stories or myths; rituals which reinforce connectivity and commitment; community which reaffirms individuals' self-worth.

And to emphasise the universal appeal of such a virtuous circle, let me cite a modernist equivalent. This comes from the writings of the philosopher Alain de Botton and his recent "Manifesto for Atheists: ten virtues for the modern age" [39]. For de Botton "the project of being good"-of being virtuous we can say_ “is as vital, or even more important than the project of being healthy” [40]. Or by extension we might paraphrase, "being virtuous is even more important than stopping climate change". His ten virtues for the atheist to cultivate include patience, hope, forgiveness and sacrifice and at least partly resonate with both Aristotle and St. Paul. There is "no scientific answer" de Botton says as to which are most important, "but the key thing is to have some kind of list on which to flex our ethical muscles" [40]. And how this is to be done bears a strong resemblance to Wright's virtuous circle: partaking in ritual, belonging to community, being inspired by human stories of faith, hope and love.

\section{Conclusions}

I have suggested that there is a renewed interest from environmental scientists and environmental social scientists in the idea of virtue and, in particular, its relationship with the sorts of questions which the challenges of climate change ask us. This interest is also evidenced, for example, through the work of environmental virtue ethicists such as Phil Cafaro [41]. I have given a short account of how the conventional plan of climate salvation is failing and how this failure has led to this new exploration of an ancient idea. I have given some token arguments of how the individual virtues of wisdom, humility, integrity, faith, hope and love have relevance as we comes to terms with the condition of a prosthetic climate and I have connected these to the collective projects of civic virtue and virtue ethics. Finally, I have suggested that the cultivation of virtue is a very practical ambition and one which can draw upon religious tradition and resources, which themselves can be partly replicated in secular contexts.

My approach to climate change taken here may seem strange to those who see the dangers of climate change as large, immanent and totalising. (Although I am not convinced this is the right way to frame these risks). And the approach may seem irrelevant to those who believe these dangers can be diffused only through various programmatic policy interventions. Yet the possible magnitude and urgency of these dangers can only be judged relative to other dangers facing people in the world, to our value commitments and to our own sense of what matters deeply. And the record to date-as I have shown-can only lower ones expectations about what conventional programmatic policy intervention around climate change can deliver.

I am suggesting something different. Rather than putting science, economics, politics or the planet at the centre of the story of climate change I am suggesting that we put the humanities-our self-understanding of human purpose and virtue — at the centre. When we talk about climate change we should not start with the latest predictions from the climate models, nor whether we have passed some catastrophic tipping point; nor whether or not the Intergovernmental Panel on Climate Change should 
be trusted. We should start by thinking about what it means to be human. What is the good life and what therefore is an adequate response to climate change? The issues about human life on a changing planet are firstly humanistic and not scientific, as recognised by the European Science Foundation's recently completed Responses to Environmental and Societal Challenges to our Unstable Earth project (note the implication in the project acronym, RESCUE, of a still-needed salvation). The Anthropocene, they concluded, “creates a completely novel situation posing fundamentally new questions, including issues related to ethics, culture, religion and human rights, and requiring new approaches and ways of thinking, understanding and acting." ([42], p. 13) This goes well beyond the capabilities of 'integrated knowledge systems' or the 'processes of Earth system governance', themes beloved by the global change research community.

My purpose in drawing attention to the idea of virtue is to appreciate the insights of the humanities and the relevance of the world's religious faiths for thinking about climate change actions. Although there are existing initiatives which seek to do this more broadly around religion and ecology (e.g., [43]), and there are recent examples of edited collections and books which explore religion and climate change [44-46], the large international global change research programmes tend to be either unaware or else distant from them [47]. Reacting to the idea of climate change is about understanding and cultivating the human imagination and developing an acute sense of good character as the telos of Man, as much as it is about applying the instruments of reason and technology. I'm not sure that this is exactly what underlies the global conversation about 'the world we want' which was an outcome of Rio+20; but perhaps it is at least a step in the right direction. We need to ask what is the telos of Anthropos; what is the goal of Man - or what are 'the aspirations of all citizens' as the call from Rio+20 put it? Is it about (human) survival—at any cost? Is it about sustained economic growth or maximising human longevity? Is it about social justice or securing some notion of political freedom? What I am suggesting here is that we need a more explicit Aristotelian contemplation on the good life, the nature of well-being and the cultivation of virtue. The question then becomes less 'the world we want' than it is 'the people we should be'.

This may well not be an easy argument to take. It requires a brave move to doubt the efficacy of solutions-oriented programmes to climate change-market fixes such as emissions trading, techno-fixes such as climate engineering, behavioural fixes such as social marketing, political fixes such as Earth system governance or even ethical fixes such as utilitarian or deontological ethics (see [48] for an argument against the latter form of programmatic universalism). And yet the cultivation and exercise of virtue is something that all of us humans can do. Indeed, perhaps it is something that all of us are called to do-to realise Calhoun's 'unused intuitions that are somewhere buried', to sustain the mutual evocation of goodness and human dignity that alone transcends our diversity. Climate change provides us this opportunity. As the esteemed Emeritus Professor of Geography at the University of the Wisconsin-Madison, Yi-Fu Tuan, has argued recently, "the good shall inherit the Earth” [49].

\section{Acknowledgments}

An earlier version of this article was delivered at Queen's University Belfast on 1 May 2013 as the Annual Religious Studies Lecture. The valuable questions and comments of John Barry, John Brewer, Jon Agnew and David Livingstone following this lecture are acknowledged. The author also benefitted 
from a Rachel Carson Writing Fellowship at LMU Munich which supported the preparation of this article. The valuable suggestions and corrections of three anonymous referees are also acknowledged.

\section{Conflicts of Interest}

The author declares no conflict of interest.

\section{References and Notes}

1. Tim Flannery. Here on Earth: a New Beginning. London: Allen \& Lane, 2011.

2. Brendon Larson. Metaphors for Environmental Sustainability: Redefining our Relationship with Nature. New Haven: Yale University Press, 2011.

3. Sheila Jasanoff. “Technologies of humility.” Nature 450 (2007): 33.

4. Alastair McIntosh. Hell and High Water: Climate Change, Hope and the Human Condition. Edinburgh: Birlinn, 2008.

5. Tim Leduc. Climate, Culture, Change: Inuit and Western Dialogues with a Warming North. Quebec: University of Ottawa Press, 2010.

6. Tom Wright. Virtue Reborn. London: SPCK, 2010.

7. The Guardian. “Ian McEwan reveals the inspiration for his 'hero' of his climate change novel Solar.” Part 1, c. 13 minutes. Available online: http://www.guardian.co.uk/science/video/2012/jul/ 27/scienceofclimatechange-ianmcewan (accessed on 27 April 2014).

8. Dan Sarewitz. “Does climate change knowledge really matter?” WIREs Climate Change 2 (2011): 475-81.

9. Naomi Oreskes, and Erik Conway. Merchants of Doubt: How a Handful of Scientists Obscured the Truth on Issues from Tobacco Smoke to Global Warming. London: Bloomsbury Publishing, 2010.

10. The Dark Mountain Project. “The manifesto.” Available online: http://dark-mountain.net/ about/manifesto/ (accessed on 27 April 2014).

11. Rowan Williams. Faith in the Public Square. London: Bloomsbury Press, 2010.

12. Eduardo Mendieta, and Jonathan Vanantwerpen, eds. The Power of Religion in the Public Sphere: Judith Butler, Jürgen Habermas, Charles Taylor, Cornel West. New York: Columbia University Press, 2011.

13. Gifford Lectures. "Professor Bruno Latour: Facing Gaia: A new enquiry into natural religion." Available online: http://www.bruno-latour.fr/node/487 (accessed on 27 June 2014).

14. Tom Crompton. Common Cause: The Case for Working with our Cultural Values. London: WWF-UK, 2010.

15. David Alberston, and Cabell King, eds. Without Nature? A New Condition for Theology. New York: Fordham University Press, 2010.

16. Sam Harris. The Moral Landscape: How Science Can Determine Human Values. London: Bantam Press, 2011.

17. Mike Hulme. Why We Disagree About Climate Change: Understanding Controversy, Inaction and Opportunity. Cambridge: Cambridge University Press, 2009. 
18. Richard D North. “Climate change (AGW): Let's take it seriously.” Available online: http://richarddnorth.com/2009/12/climate-change-agw-lets-take-it-seriously/ (accessed on 27 April 2014).

19. Charles Taylor. A Secular Age. Cambridge: Harvard University Press, 2007.

20. Ronald Sandler, and Phil Cafaro. Environmental Virtue Ethics. Lanham: Rowman \& Littlefield, 2005.

21. Ronald Sandler. Character and Environment: A Virtue-Oriented Approach to Environmental Ethics. New York: Columbia University Press, 2007.

22. Melissa Lane. Eco-Republic: Ancient Thinking for a Green Age. Oxford: Peter Lang, 2011.

23. Alastair MacIntyre. After Virtue, 3rd ed. Notre Dame: University of Notre Dame Press, 2007.

24. Guy Axtell, and Philip Olson. "Recent Work in Applied Virtue Ethics.” American Philosophical Quarterly 49 (2012): 183-203.

25. Dragos Simandan. "The wise stance in human geography.” Transactions of the Institute of British Geographers 36 (2011): 188-92.

26. Bent Flyvbjerg. Making Social Science Matter: Why Social Inquiry Fails and How It Can Succeed Again. Cambridge: Cambridge University Press, 2001.

27. Robert Sternberg. "WICS: a model of positive educational leadership comprising wisdom, intelligence and creativity synthesized.” Educational Psychology Review 17 (2005): 191-262.

28. Clive Hamilton. Earthmasters: Playing God with the Climate. New Haven: Yale University Press, 2013.

29. Justin Oakley, and Dean Cocking. Virtue Ethics and Professional Roles. Cambridge, Cambridge University Press, 2001.

30. Allen Thompson. "Radical Hope for Living Well in a Warmer World.” Journal of Agricultural Environmental Ethics 23 (2010): 43-59.

31. Edward Wilson. Biophilia: The Human Bond With Other Species. Cambridge: Harvard University Press, 1984.

32. C. S. Lewis. The Four Loves. London: Fount Paperbacks/Collins, 1977.

33. Proverbs 11:11 (New International Version).

34. Colin Farrelly. Justice, Democracy and Reasonable Agreement. New York: Palgrave Macmillan, 2007.

35. Dale Jamieson. Reason in a Dark Time: Why the Struggle against Climate Change Failed-And What it Means for Our Future. Oxford/New York: Oxford University Press, 2014.

36. Stephen Gardiner. "Ethics and climate change: An introduction." WIREs Climate Change 1 (2010): 54-66.

37. Liezl van Zyl. "Virtue Theory and Applied Ethics." South African Journal of Philosophy 21 (2002): 133-44.

38. Operation Noah. "Why climate change is a confessional question." Available online: http://www.operationnoah.org/confessional-question (accessed on 27 April 2014).

39. Alain de Botton. Religion for Atheists: A Non-Believers Guide to the Uses of Religion. London: Vantage, 2013.

40. Alain de Botton. Interview on BBC Radio 4 Saturday Live, 16 March 2013. 
41. Phil Cafaro. "Introduction: Special Issue on Environmental Virtue Ethics." Journal of Agricultural and Environmental Ethics 23 (2010): 3-7.

42. European Science Foundation. Responses to Environmental and Societal Challenges to our Unstable Earth. Strasbourg: European Science Foundation, 2012.

43. “The Forum on Religion and Ecology at Yale.” Available online: http://fore.research.yale.edu (accessed on 19 June 2014).

44. Dieter Gerten, and Sigurd Bergmann, eds. Religion in Environmental and Climate Change: Suffering, Values, Lifestyles. New York/London: Continuum Press, 2012.

45. Robin Veldman, Andrew Szasz, and Randy Haluza-Delay, eds. How the World's Religions are Responding to Climate Change: Social Scientific Investigations. Abingdon/New York: Routledge, 2013.

46. Michael Northcott. Climate Change and Christian Ethics. Cambridge, Cambridge University Press, 2013.

47. Mike Hulme. “Meet the Humanities.” Nature Climate Change 1 (2011): 177-79.

48. Menno Kamminga. "The Ethics of Climate Politics: Four Modes of Moral Discourse Environmental Politics 17 (2008): 673-92.

49. Yi-Fu Tuan. “The good inherit the Earth.” In Envisioning Landscapes, Making Worlds: Geography and the Humanities. Edited by Stephen Daniels, Dydia DeLyser, Nicholas Entrikin and Doug Richardson. Abingdon/New York: Routledge, 2007, pp. 127-40.

(C) 2014 by the author; licensee MDPI, Basel, Switzerland. This article is an open access article distributed under the terms and conditions of the Creative Commons Attribution license (http://creativecommons.org/licenses/by/3.0/). 